FREIRIA, L.B. et al. Impacto da adubação nitrogenada nas características morfofisiológicas de gramíneas do gênero Brachiaria e Cynodon em pastejo e corte. PUBVET, Londrina, V. 8, N. 8, Ed. 257, Art. 1706, Abril, 2014.

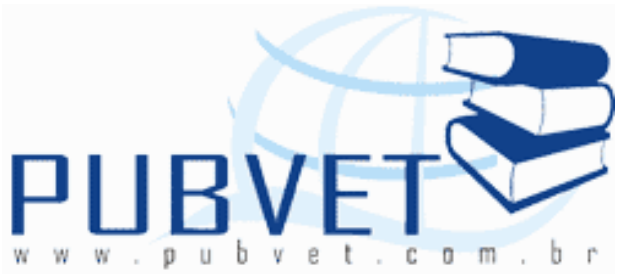

PUBVET, Publicações em Medicina Veterinária e Zootecnia.

\title{
Impacto da adubação nitrogenada nas características morfofisiológicas de gramíneas do gênero Brachiaria e Cynodon em pastejo e corte
}

\section{Lucien Bissi da Freiria ${ }^{1}$, Adriano Jorge Possamai ${ }^{1}$, Alan Carlos Barboza ${ }^{2}$, Joanis} Tilemahos Zervoudakis ${ }^{3}$

${ }^{1}$ Discentes mestrado no programa de Pós-graduação em Ciência Animal (PPGCA -UFMT - Cuiabá).

${ }^{2}$ Discente Graduação em Zootecnia pela Universidade Federal de Mato Grosso

- Cuiabá

${ }^{3}$ Professor do Departamento de Ciências Básicas e Produção Animal da Universidade Federal de Mato Grosso (DCBPA -UFMT- Cuiabá).

Autor para correspondência: Lucienbissi@hotmail.com

\section{Resumo}

Esta revisão concentra-se em comparar características morfofisiológicas de gramíneas do gênero Brachiaria e Cynodon em respostas de adubação nitrogenada em pastejo ou corte. O manejo de pastagem tem como aspecto central manter o equilíbrio da área foliar, que é responsável pela interceptação de luz e fixação do carbono e a parte de remoção de tecidos foliares para o consumo animal. Deste modo, torna-se fundamental conhecer não somente o comportamento dos animais, mas também as características morfofisiológicas das plantas para se efetivar um manejo correto, com uma maior intensificação do uso.Sendo assim, torna-se necessário um maior entendimento de como 
FREIRIA, L.B. et al. Impacto da adubação nitrogenada nas características morfofisiológicas de gramíneas do gênero Brachiaria e Cynodon em pastejo e corte. PUBVET, Londrina, V. 8, N. 8, Ed. 257, Art. 1706, Abril, 2014.

essas ferramentas poderão ser usadas de forma combinada no dia-a-dia da propriedade rural.

Palavras-chave: Corretivos; eficiência pastejo; produção forrageira.

\title{
Impact of nitrogen in the morphophysiological characteristics of Brachiaria and Cynodon in grazing and cutting
}

\begin{abstract}
This review will focus on comparing characteristics morphophysiological of grass Brachiaria and Cynodon on responses from nitrogen fertilization of grazing or cutting. The pasture management has as a central aspect to keep balance of the leaf area, which is responsible for light interception and carbon sequestration and the removal of leaf tissues for intake animal. Thus, it becomes essential to know not only the behavior of animals, but also the morphophysiological characteristics of the plants to be effective one correct management, with greater intensification of use. Thus, it becomes necessary to a better understanding of how these tools can be used in combination in the day-to-day farm.
\end{abstract}

Keywords: Correctives; efficiency grazing; forage production.

\section{Introdução}

A pecuária brasileira baseia-se na utilização de pastagens tropicais, pois o país oferece boas condições edafoclimáticas e grandes áreas disponíveis para a atividade (Medeiros et al., 2011). E representam umas das principais fontes de nutrientes para o rebanho bovino (DOLEJAL et al., 2009), devido ao seu baixocusto de produção em relação aos concentrados, o que se tornaa forma mais prática e econômica de alimentação (ALENCAR et al., 2009).

Mesmo por ser uma alimentação de menor custo, define-se que o potencial de produção de uma planta forrageira é determinado geneticamente, porem sugere que ainda há muito a se descobrir para que esse potencial seja 
FREIRIA, L.B. et al. Impacto da adubação nitrogenada nas características morfofisiológicas de gramíneas do gênero Brachiaria e Cynodon em pastejo e corte. PUBVET, Londrina, V. 8, N. 8, Ed. 257, Art. 1706, Abril, 2014.

alcançado (FAGUNDES et al. (2005). A predição para explorar o potencial máximo da planta, é necessário conhecer, entende e controlar suas características morfofisiológicas por meio de estudos morfogênicos associados ao rígido controle da altura do dossel, definindo, então, os limites de tolerância e resistência à desfolha nos mais variados ambientes (SOUSA, 2009; SANTOS JR. et al., 2004).

Assim, a anatomia vegetal quantitativa tem sido utilizada como ferramenta complementar nas pesquisas de avaliação das plantas forrageiras. Portanto, a dinâmica do aproveitamento das diferentes estruturas internas das forrageiras pode ser melhor compreendida quando complementada com os estudos de anatomia vegetal (Medeiros et al., 2011).

A morfogênese, em um pasto vegetativo, pode ser descrita por três características básicas: o aparecimento de folhas, o alongamento de folhas e a duração de vida da folha. A combinação dessas variáveis morfogênicas básicas é responsável pelas principais características estruturais do pasto: tamanho da folha, densidade populacional de perfilhos e número de folhas vivas por perfilho (PENA et al., 2009).

Os perfilhos são considerados as unidades de crescimento de gramíneas forrageiras, de forma que o pasto é uma população de perfilhos, e para que este se torne perene e persistente é preciso que haja um balanço entre o aparecimento e morte de perfilhos ao longo do ano, dinâmica a qual permite que o pasto se adapte a diferentes condições de manejo (PENA, 2010; PATÊS et al., 2007).

Idealmente, deve-se procurar o equilíbrio entre a manutenção de área foliar suficiente para fotossíntese e a colheita de grandes quantidades de folhas antes que estas venham a senescer, de forma a favorecer uma exploração racional e eficiente das pastagens (DIFANTE et al., 2011).

As variáveis morfogênicas são afetadas pela disponibilidade de recursos de crescimento como água, luz, nitrogênio e temperatura. As variáveis estruturais, por sua vez, são afetadas pelas modificações nas respostas morfogênicas e pela freqüência e intensidade de corte ou pastejo (DIFANTE et 
FREIRIA, L.B. et al. Impacto da adubação nitrogenada nas características morfofisiológicas de gramíneas do gênero Brachiaria e Cynodon em pastejo e corte. PUBVET, Londrina, V. 8, N. 8, Ed. 257, Art. 1706, Abril, 2014.

al., 2008). Ou seja, a combinação das variáveis morfogênicas é determinante nas principais características estruturais da pastagem, sendo elas, tamanho de folha, densidade populacional de perfilhos e número de folhas vivas por perfilho, que em resumo determina o IAF, altura e massa da forragem (LEMAIRE \&AGNUSDEI, 2000).

Entre os fatores citados, um de aplicabilidade com interferência humana destaca-se a adubação com importância sobre a produção das forrageiras (ANDRADE et al, 2009). O uso de fertilizantes posiciona-se como uma prática de manejo de pastagens que têm proporcionado aumento na capacidade de suporte animal na propriedade e melhoria de desempenho econômico, sobretudo os fertilizantes nitrogenados (FAGUNDES et al., 2011).

Nitrogênio, na maioria das culturas, é o nutriente que mais limita o desenvolvimento, a produtividade e a biomassa desta, que pode variar quanto ao nível utilizado e a espécie (Lopes et al., 2004). É o nutriente absorvido em maiores quantidades pela maioria das culturas, especialmente pelas gramíneas, e está entre as deficiências nutricionais mais frequentes que ocorrem nas culturas (ANDRADE et al, 2009). Pode ser considerado como o principal nutriente para plantas, sendo exigido em grandes quantidades (CECATO et al., 2001).

O suprimento de nitrogênio interfere na rebrota da forrageira após a desfolhação, pois altera as características e adaptações morfofisiológicas apresentadas pelas plantas (ALVES et al., 2008). Além disso, proporciona um aumento na capacidade de suporte das pastagens, uma vez que acelera a formação e o crescimento de novas folhas e aumenta o vigor da rebrota (DA SILVA et al., 2012). Em virtude da associação da adubação nitrogenada e do seu papel em várias características morfogênicas, envolvendo a dinâmica de folhas e perfilhos, torna-se necessária a avaliação dos efeitos deste nutriente sobre as gramíneas (FAGUNDES et al., 2011).

O objetivo da presente revisão é abordar sobre o impacto da adubação nas características morfofisiológicas de gramíneas do gênero Brachiaria e Cynodon em pastejo e corte. 
FREIRIA, L.B. et al. Impacto da adubação nitrogenada nas características morfofisiológicas de gramíneas do gênero Brachiaria e Cynodon em pastejo e corte. PUBVET, Londrina, V. 8, N. 8, Ed. 257, Art. 1706, Abril, 2014.

\section{Gênero Brachiaria}

As pastagens são utilizadas como alimentação exclusiva de aproximadamente $90 \%$ do rebanho bovino nacional (ANUALPEC, 2009). Atualmente, as pastagens ocupam $48 \%$ dos 354 milhões de hectares agricultáveis existentes no país, constituindo o principal uso da terra, seguido de matas e florestas (27\%) e lavouras (21\%) (SOUZA 2012). E Aproximadamente 80 a $90 \%$ das áreas de pastagens no Brasil são constituídas por forrageiras do gênero Brachiaria (Boddeyet al., 2004).

Neste sentido novos estudos estão sendo realizados para melhorar a eficiência de utilização destas. Sendo avaliadas características morfogênicas e estruturais do dossel, relacionados com corte ou pastejo (Da Silva e Nascimento jr., 2007).

Variáveis estas, como o aparecimento de folhas, o alongamento de folhas e a duração de vida da folha (Morfogênicas) e tamanho da folha, densidade populacional de perfilhos e número de folhas vivas por perfilho (estruturais), e a combinação destas implicam no índice de área foliar (IAF), altura e massa de forragem se tornaram importantes para determinação de estratégias de manejos de adubação em relação ao corte e pastejo.

\subsection{Taxa de aparecimento foliar}

Castagnaraet al. (2011a) observaram adubações nitrogenadas provocam efeitos sobre a características morfogênicas e estruturais de gramíneas do gênero Brachiaria. Alexandrino et al. (2005) ao avaliarem características morfogênicas da Brachiaria brizantha cv. Marandu submetidas a diferentes doses de nitrogênio $\left(0,45,90,180,360 \mathrm{mg} / \mathrm{dm}^{3}\right)$ e duas frequências de corte (a cada 14 e 28 dias), com altura de corte fixo $(10 \mathrm{~cm}$ do solo), para taxa de aparecimento foliar (TApF) obtiveram resultados em que esta variável foi $58,7 \%$ maior na menor frequência de corte, devido o cartucho da bainha ser reduzido, o que diminui o espaço em que a folha percorre para emergir, e o 
FREIRIA, L.B. et al. Impacto da adubação nitrogenada nas características morfofisiológicas de gramíneas do gênero Brachiaria e Cynodon em pastejo e corte. PUBVET, Londrina, V. 8, N. 8, Ed. 257, Art. 1706, Abril, 2014.

aumento das doses de $\mathrm{N}$ também influenciou positivamente na TApF (Figura $1)$.

Algo semelhante foi encontrado por Silva et al (2009) ao determinarem as características morfogênicas e estruturais de Brachiaria brizantha e $B$. decumbens adubados com diferentes doses de nitrogênio $(N)$, em casa de vegetação, com corte de uniformização de $5 \mathrm{~cm}$ do solo, encontraram um efeito quadrático da adubação nitrogenada na TApF, que foi maior com dose de $169 \mathrm{mg} / \mathrm{dm}^{3}$ de $\mathrm{N}(0,15$ folha/dia/perfilho), e definem que o incremento de $\mathrm{N}$ aumenta a produção de novas células, que tem reflexo positivo no número de folhas por planta (Figura 2).

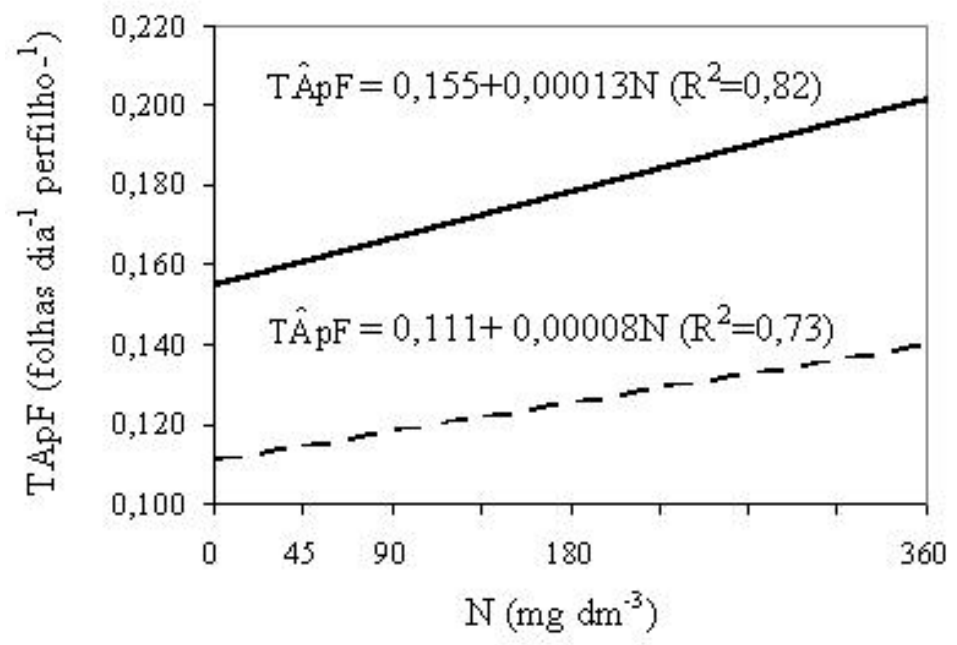

Figura 1: Estimativa da taxa de aparecimento foliar (TApF) da Brachiaria brizantha cv. Marandu para as frequências de corte $\overline{1} \overline{4}$ dias ( ) e 28 dias ( ) , em função das doses de nitrogênio $(N)$. Fonte:Alexandrino et al. (2005). 
FREIRIA, L.B. et al. Impacto da adubação nitrogenada nas características morfofisiológicas de gramíneas do gênero Brachiaria e Cynodon em pastejo e corte. PUBVET, Londrina, V. 8, N. 8, Ed. 257, Art. 1706, Abril, 2014.

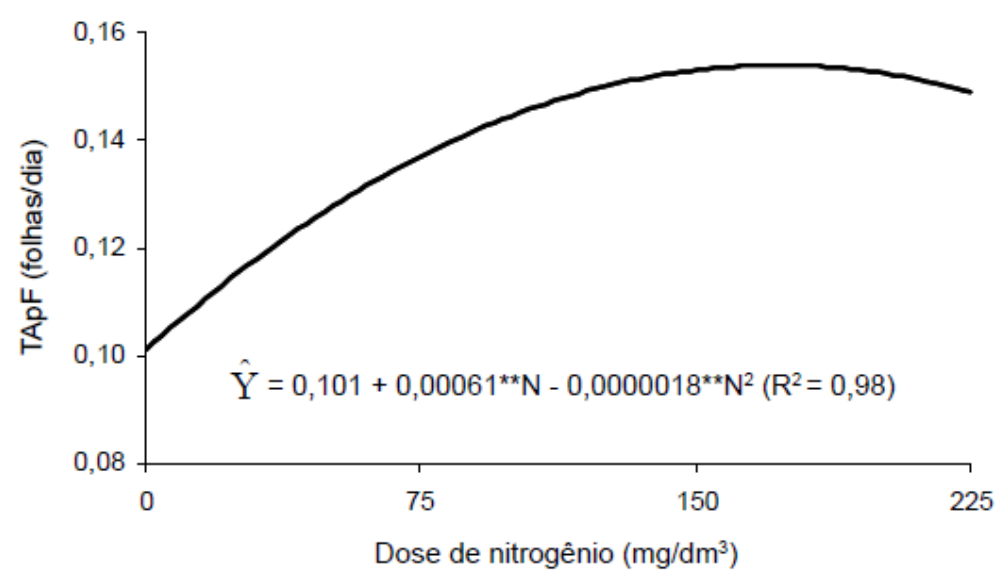

Figura 2: Estimativa da média das gramíneas Brachiaria brizantha e $B$. decumbensda taxa de aparecimento foliar (TApF), em função das doses de nitrogênio (N). Fonte:Silvaet al. (2009).

Alexandrino et al. (2004) ao avaliar características morfogênicas e estruturais na rebrotação da Brachiaria brizantha cV. Marandu submetida a três doses de nitrogênio $\left(0,20\right.$ e $40 \mathrm{mg} \mathrm{dm}^{-3}$ semana $^{-1}$ de $\mathrm{N}$ ), observaram que com o aumento do suprimento de $\mathrm{N}$, provocou incremento linear positivo à TApF (0,0819, 0,1180 e 0,1430 folhas/dia), e verificou-se um efeito de tendência linear para o comprimento médio da folha (CMF) com aumento das doses de N. Já Alexandrino et al. (2005) encontraram com aumento das doses de $\mathrm{N}$ um incremento de forma quadrática para CMF, com uso de doses mais expressivas, ao estimar-se o máximo para dose de $331,68 \mathrm{mg} \mathrm{dm}^{-3}$, e os cortes mais frequentes comprometeram o CMF, devido o menor tempo de rebrotação.

Souza (2009) ao avaliar TApF e CMF para Brachiaria brizantha cv. Xaraés, não encontrou efeito para essas duas variáveis com diferentes alturas de corte (15, 20 e 25 cm), utilizando a mesma dosagem de adubação nitrogenada (200 $\mathrm{kg} / \mathrm{ha}$ ) em todos os tratamentos, com intervalos de corte em função da interceptação luminosa (95\%), o que reforça que essas duas características variam em função da adubação nitrogenada e tempo de rebrotação. 
FREIRIA, L.B. et al. Impacto da adubação nitrogenada nas características morfofisiológicas de gramíneas do gênero Brachiaria e Cynodon em pastejo e corte. PUBVET, Londrina, V. 8, N. 8, Ed. 257, Art. 1706, Abril, 2014.

\subsection{Filocrono}

Outra variável importante aliada a TApF é a quantificação do filocrono, definição inversa da TApF, ou seja, o tempo (em dias)para aparecimento de duas folhas sucessivas noperfilho, influenciada pela adubação nitrogenada. Segundo Alexandrino et al. (2004) definiu que adubação nitrogenada pode interferir extensão do filocrono, de forma que reduz o aumento deste, pois encontraram valores de 12,$20 ; 8,47$; e 6,99 dias folha ${ }^{-1}$, respectivamente, para as plantas que receberam 0,20 e $40 \mathrm{mg} / \mathrm{dm}^{-3}$ semana $^{-1}$ de N. Silva et al. (2009) encontrou valores de filocrono menores com adubação nitrogenada de $160 \mathrm{mg} \mathrm{dm}^{-3}$ para $B$. brizantha, 6,8 dias/folha e para $b$. decumbens, 6,0 dias/folha.

Segundo Oliveira et al. (2000) à medida que avança o estádio de desenvolvimento da planta, após passar por uma fase de intenso aparecimento de folhas e perfilhos, observa-se contínuo alongamento do pseudocolmo, resultando em aumento do filocrono de folhas individuais, pois a folha necessita percorrer distância maior entre o meristema apical e a extremidade do pseudocolmo.

\subsection{Taxa de alongamento foliar}

Para a taxa de alongamento foliar (TAIF), Silva et al.(2009) observaram influencia da adubação nitrogenada na TAlF, pois a $B$. decumbens respondeu de forma positiva até a dose de $182 \mathrm{mg} / \mathrm{dm}^{3}$ de $\mathrm{N}$, com TAlF de 17,1 $\mathrm{mm} /$ folha/dia e A B. brizantha, no entanto, apresentou o maior valor (25,36 $\mathrm{mm} /$ folha/dia) na dose de $222 \mathrm{mg} / \mathrm{dm}^{3} \mathrm{de} \mathrm{N}$.

Da Silva et al. (2012) ao avaliar as características morfogênicas e estruturais do pasto de Brachiaria decumbens, submetido a intensidades (15 e $25 \mathrm{~cm}$ ), frequências de corte (40 e $50 \mathrm{~cm}$ ) e adubação nitrogenada (0 e 100 $\mathrm{kg} / \mathrm{ha}$ ), encontraram efeito significativo da interação intensidade de corte $x$ adubação para TAIF, o maior valor de TALF com adubação de $100 \mathrm{~kg} / \mathrm{ha}$, foi 
FREIRIA, L.B. et al. Impacto da adubação nitrogenada nas características morfofisiológicas de gramíneas do gênero Brachiaria e Cynodon em pastejo e corte. PUBVET, Londrina, V. 8, N. 8, Ed. 257, Art. 1706, Abril, 2014.

para intensidade de corte de $25 \mathrm{~cm}(0,43 \mathrm{~cm} /$ folha/dia) e menor valor para a intensidade de corte de $15 \mathrm{~cm}(0,25 \mathrm{~cm} /$ folha/dia $)$.

Alexandrino et al. (2005) ao avaliar TAlF, demostraram a influencia das doses de adubação e frequências de corte (14 e 28 dias) a essa característica morfogênica, ocorreu com aumento das doses de $\mathrm{N}$ um incremento de forma quadrática, ao atingir o máximo com a dose $\mathrm{N}$ de 293,43 $\mathrm{mg} \mathrm{dm}^{-3}$, e corte mais frequentes (14 dias) menor a TAIF. Sousa (2009) encontrou o maior valor médio para essa variável para altura de corte $15 \mathrm{~cm}(1,50 \mathrm{~cm} /$ perfilho/dia), e menor para as alturas de corte de $20 \mathrm{~cm}$ (1,20 cm/perfilho/dia) e $25 \mathrm{~cm}$ (1,30 $\mathrm{cm} /$ perfilho/dia), pois corte foram realizados quando o dossel atingia $95 \%$ de interceptação luminosa (figura 3), de forma que a altura de corte de $15 \mathrm{~cm}$ se provia de maior tempo de rebrotação (25,8 dias).

Para Casagrande (2007) ao avaliar características morfogênicas do dossel de Brachiariabrizantha cv. Marandu manejada com diferentes ofertas de forragem (4, 7, 10 e 13\% do PC) sob lotação intermitente, obtiveram resultados em que a TAIF não foi afetado pelas ofertas de forragem, mas pode observar variações TAIF em relação aos intempéries climáticos (precipitação pluvial).

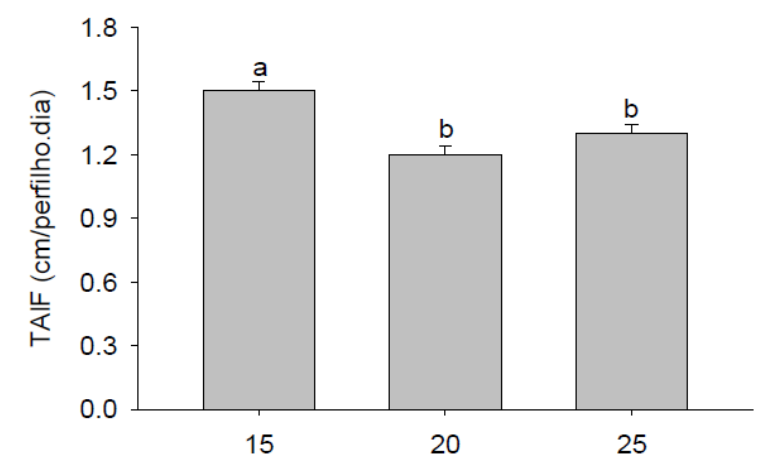

Figura 3: Taxa de alongamento de folhas $\left(\mathrm{cm}\right.$ perfilho $\left.\mathrm{dia}^{-1}\right)$ em capim Xaraés cortado a 15, 20, $25 \mathrm{~cm}$ do solo ao atingir $95 \%$ de IL durante a rebrotação. Fonte: Sousa (2009). 
FREIRIA, L.B. et al. Impacto da adubação nitrogenada nas características morfofisiológicas de gramíneas do gênero Brachiaria e Cynodon em pastejo e corte. PUBVET, Londrina, V. 8, N. 8, Ed. 257, Art. 1706, Abril, 2014.

Alexandrino et al. (2004) encontro um efeito linear positivo na TAIF em função das doses de nitrogênio (TAlF $=0,7875 \mathrm{~N}+19,37, \mathrm{r}^{2}=0,999, \mathrm{~mm}^{2} \mathrm{dia}^{-}$ $\left.{ }^{1}\right)$. Os mesmos autores recomendam com doses de 0,20 e $40 \mathrm{mg} \mathrm{dm}^{-3}$ semana $^{-1}$ de $\mathrm{N}$, cortes com 32, 26 e 20 dias de rebrotação, para Brachiaria brizantha cv. Marandu, para não ocorrer perdas por senescência. Cecatoet al. (2000), definem que as quantidades crescentes de nitrogênio e fósforo proporcionaram resposta positiva no vigor da rebrota do dossel. Desta forma, o aumento das doses de aplicação nitrogenada,maior intensidade de corte e maior frequência de corte influenciam positivamente na TAIF.

\subsection{Taxa alongamento do colmo}

Quanto ao alongamento do colmo (AIC),pode-se reduzir coma intensidade decorte, vale lembrar que esse manejo não só importante para evitar o aumento do colmo, como também influenciar na TApF, filocrono, CMF e TAIF, características já citadas.

Sousa (2009) encontrou maior alongamento do colmo com maior altura de corte $25 \mathrm{~cm}(0,086 \mathrm{~cm} /$ perfilho/dia) em relação a menor altura de corte 15 $\mathrm{cm}(0,056 \mathrm{~cm} /$ perfilho/dia). Difanteet al. (2011) ao avaliar o acúmulo de forragem e as características morfogênicas e estruturais do capim-marandu submetido a combinações de alturas (15 e $30 \mathrm{~cm}$ ) e intervalos de corte, com adubação nitrogenada de $50 \mathrm{~kg} / \mathrm{ha}$, observaram que o acúmulo de colmos diferiu apenas entre intervalos de corte, e foi maior quando as plantas foram cortadas após o surgimento de cinco folhas por perfilho $\left(0,6 ; 0,9 ;\right.$ e $2,3 \mathrm{~kg} / \mathrm{m}^{2}$ de MS para três, quatro e cinco folhas novas surgidas por perfilho, respectivamente).

Casagrande (2007) ao avaliar a taxa de alongamento de colmo (TAIC), observou um aumento em função da oferta de forragem (OF), ou seja, OF de $13 \%$ do PC aumenta a massa de forragem, mas provoca um sombreamento mútuo entre os perfilhos acarretando em uma intensa competição por luz, e prejudica a estrutura do dossel com uma menor relação folha/colmo.Van Soest 
FREIRIA, L.B. et al. Impacto da adubação nitrogenada nas características morfofisiológicas de gramíneas do gênero Brachiaria e Cynodon em pastejo e corte. PUBVET, Londrina, V. 8, N. 8, Ed. 257, Art. 1706, Abril, 2014.

(1994) define que quanto maior a relação folha/colmo, maior o valor nutritivo da forragem, pois as folhas são a fração da planta forrageira com maior digestibilidade, e o inverso, menor valor nutritivo, pela maior presença de colmo e material morto (DA SILVA E NASCIMENTO JR., 2007).

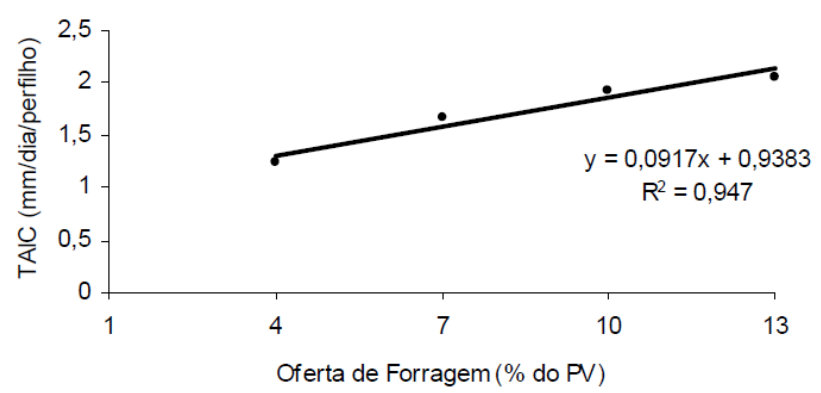

Figura 4: Taxa de alongamento de colmo (TAIC) de Brachiaria brizantha cv. Maranduem função da oferta de forragem, em pastagens manejadas sob pastejointermitente, no período das águas. Fonte: Casagrande (2007).

Castagnaraet al. (2011) confirmam que o aumento da produção de forragem com o aumento a altura do dossel, provoca o aumento da produção de colmos, por se alongarem. Gonçalves et al. (2002) definem que cortes a intervalos menores resultam em baixas produções de matéria seca, menor alongamento do colmo, ou seja, maior relação lâmina: colmo (L/C), que por consequência, determina um dossel com elevado valor nutritivo.

\subsection{Produção de matéria seca}

A produção de matéria seca também possui respostas à adubação nitrogenada, normalmente tem efeito linear dentro de certos limites que variam de acordo com o potencial genético das diferentes espécies (CARARD et al, 2008; MARANHÃO et al, 2009). 
FREIRIA, L.B. et al. Impacto da adubação nitrogenada nas características morfofisiológicas de gramíneas do gênero Brachiaria e Cynodon em pastejo e corte. PUBVET, Londrina, V. 8, N. 8, Ed. 257, Art. 1706, Abril, 2014.

Araújo et al (2009) puderam notar que a adubação nitrogenada (60 $\mathrm{kg} / \mathrm{ha}$ ) incrementou a altura do dossel. Cecatoet al. (2000), definem com o aumento na quantidade de nitrogênio $(0,200,400$ e $600 \mathrm{~kg} / \mathrm{ha})$ e de fósforo (0,50,100, 150 e 200 kg/ha) em gramínea do gênero brachiária, provoca um aumento na produção de matéria seca total, de forma que melhora a qualidade da forragem com melhor aproveitamento pelo animal.

Da Silva et al. (2012) encontraram uma relação entre intensidade e frequência de corte $(15-40,25-40,15-50,25-50)$ para produção de matéria seca total com adubação nitrogenada de $100 \mathrm{~kg} / \mathrm{ha}$, sendo a maior média de PMST foi de 5,24 ton/ha para intensidade e frequência de corte 25-50, nesta altura de $50 \mathrm{~cm}$ houve maior tempo para acumular biomassa se comparado com as demais intensidades de corte, entretanto isto só foi observado para o resíduo $25 \mathrm{~cm}$, evidenciando que neste há uma maior reserva de carboidratos que possibilitam uma rebrota mais vigorosa.

A interação positiva do nitrogênio e do fósforo na produção das plantas forrageiras diz respeito ao fósforo, que tem grande importância na formação de raízes e no perfilhamento, e ao nitrogênio, que, além de melhorar o perfilhamento, atua no incremento da produção de colmos e folhas, e, consequentemente, na matéria seca total. (Cecatoet al., 2000).

O crescimento das plantas adubadas, ou seja, o aumento da produção de massa seca é sempre maior, graças à presença de perfilhos jovens, que apresentam maior crescimento comparado aos primeiros perfilhos (perfilhos mais velhos), que já passaram pela fase linear e estão próximos ao platô da curva de crescimento sigmoide (ALEXANDRINO et al., 2004). A maior produção de matéria verde e matéria seca é em parte consequência do incremento no número de folhas por perfilho e na altura da forragem (Castagnaraet al., 2011a). 
FREIRIA, L.B. et al. Impacto da adubação nitrogenada nas características morfofisiológicas de gramíneas do gênero Brachiaria e Cynodon em pastejo e corte. PUBVET, Londrina, V. 8, N. 8, Ed. 257, Art. 1706, Abril, 2014.

\subsection{Densidade populacional de perfilhos}

Em pastagens com altas densidades de plantas, os cortes estimulam o perfilhamento, mesmo sem a remoção do meristema apical, pois aumenta a luminosidade que chega às gemas basilares (ALEXANDRINO et al., 2005). Esses mesmos autores ao avaliar duas frequências de corte (14 e 28 dias) definiram que cortes mais frequentes interferiram negativamente no número de perfilhos. Pena (2010) concluíram que a frequência de pastejo é determinante para aceleração da renovação de tecidos e perfilhos.

Silva et al. (2009) ao avaliar diferentes doses de $\mathrm{N}$ para número de perfilhos por planta, encontraram na espécie $B$. decumbens, o maior número de perfilhos por planta (23,8 perfilhos) com a dose de $184 \mathrm{mg} / \mathrm{dm}^{3}$ de $\mathrm{N}$, e a B. brizantha, o maior número de perfilhos por planta (12,8 perfilhos) foi estimado na dose de $179 \mathrm{mg} / \mathrm{dm}^{3}$ de N. E concluíram que A Brachiaria decumbens e a Brachiaria brizantha respondem de forma crescente até a dose de $190 \mathrm{mg} / \mathrm{dm} 3$ de nitrogênio. O processo de senescência dessas forrageiras acelera com o aumento das doses de nitrogênio, reduzindo a duração de vida das folhas.

Difanteet al. (2008) avaliar a dinâmica do perfilhamento do capimmarandu submetido a duas alturas (15 e $30 \mathrm{~cm}$ do solo) e três intervalos (aparecimento de três, quatro e cinco folhas por perfilho) de corte, pode observar que o corte a $15 \mathrm{~cm}$ aumenta a velocidade de renovação de tecidos, elevando as taxas de aparecimento e de mortalidade de perfilhos.

Casagrande (2007) ao avaliar oferta de forragem, sugere que com maiores pressões de pastejo ( $4 \%$ do PC), houve um maior controle da densidade populacional de perfilhos reprodutivos (DPPr), por sua decapitação provocada pelo pastejo antecedendo sua emergência e maior densidade populacional de perfilhos vegetativos, por maior contato com a luminosidade em suas gemas basilares, e em pressões intermediárias ( 7 e 10\% do PC) houve uma maior DPPr, por haver uma menor decapitação desses perfilhos e também pela maior capitação luminosa na base do dossel, já em pressões de 
FREIRIA, L.B. et al. Impacto da adubação nitrogenada nas características morfofisiológicas de gramíneas do gênero Brachiaria e Cynodon em pastejo e corte. PUBVET, Londrina, V. 8, N. 8, Ed. 257, Art. 1706, Abril, 2014.

pastejo menores (13\% do PC), ocorreu menor DPPr, devido à maior porte de altura, que provavelmente aumentou a interceptação de luz pelo dossel. Consequentemente, a quantidade de luz incidente na base deste dossel foi inferior, o que dificulta o desenvolvimento das gemas basais.

A maior intensidade de corte $(15 \mathrm{~cm})$ promove maior abertura do dossel forrageiro em relação às gramíneas manejadas com menores intensidades de cortes $(30 \mathrm{~cm})$, o acarreta uma maior intercepção de luz na base do dossel, o que favorece a maior taxa de aparecimento de perfilhos basilares (Difanteet al., 2008), e alturas de corte maiores $(30 \mathrm{~cm}$ ) e maiores intervalos de corte (5 folhas surgidas por perfilhos), aumentam a competição por luz, o que reduz a quantidade e a qualidade da radiação solar que chega à base das plantas priorizando o crescimento de perfilhos existentes, reduzindo o aparecimento de novos perfilhos (Difante et al., 2011).

A gramíneas mantidos sob regime intenso de desfolhação apresentam perfilhos com folhas mais curtas e maior densidade populacional de perfilhos pequenos (Matthew et al., 2000; Medeiros et al, 2011).

Alexandrino et al. (2005) ao avaliar doses crescentes de nitrogênio após cortes, pode constatar que a densidade de perfilhos foi afetada positivamente pelas doses de $\mathrm{N}$, isso também foi observado por Casagrande (2007).

Alexandrino et al. (2004), de maneira geral, definiram que a presença de $\mathrm{N}$ promove maior peso médio (PMP) e densidade populacional de perfilhos (DPP), e o perfilhamento de plantas sem suprimento de $\mathrm{N}$ fica debilitado. $\mathrm{E}$ ainda em doses maiores de $\mathrm{N}$ ( $80 \mathrm{~kg} / \mathrm{ha} / \mathrm{semana})$ pode provocar uma maior DDP e uma redução no peso médio de perfilhos em ralação a doses menores (40 kg/ha/semana). E Caradet al. (2008) definiu que o número e peso de perfilho de uma planta determinam sua produtividade, mas varia inversamente em função do genótipo (características) e do manejo, ligado tanto com as alturas de corte ou pressões de pastejos, como também tempo de rebrota e/ou frequências de pastejo. 
FREIRIA, L.B. et al. Impacto da adubação nitrogenada nas características morfofisiológicas de gramíneas do gênero Brachiaria e Cynodon em pastejo e corte. PUBVET, Londrina, V. 8, N. 8, Ed. 257, Art. 1706, Abril, 2014.

\subsection{Recomendações}

A produção de matéria seca é outra variável importante para respostas das modificações morfogênicas e da estrutura do pasto, mas devem ser analisadas com cautela, pois Difanteet al (2011) encontrou valores produtivos para intervalos de corte maiores, mas, contudo, apresentaram maior participação de colmos e de material morto na forragem produzida, componentes esses que dificultam a capacidade de apreensão de forragem e, consequentemente, o consumo voluntário de animais em pastejo, podendo comprometer a eficiência de utilização da forragem produzida, e concluíram pastos manejados com intervalo de corte correspondente a três folhas surgidas por perfilho, independentemente da altura de corte avaliada, acumulam elevada quantidade de folhas, componente altamente desejável para alimentação animal.

E também concluíram que a maior eficiência de utilização dos pastos de capim-marandu foi alcançada com cortes a $15 \mathrm{~cm}$ (menor período de rebrotação, altura pré-corte, alongamento de colmo e tamanho final da folha e maior densidade populacional de perfilhos).

Bauer et al. (2011) ao avaliar a produção e a estrutura do dossel de cinco forrageiras do gênero Brachiaria ( $B$. brizantha cv. Marandu, $B$. brizantha cv. Xaraés, $B$. decumbens, $B$. ruziziensise $B$. hibrida $\mathrm{cv}$. Mulato), submetidas às intensidades de corte de 10 e $20 \mathrm{~cm}$, com intervalo de corte fixado a cada 30 dias, e adubação nitrogenada de $200 \mathrm{~kg} / \mathrm{ha}$, fracionada em quatro aplicações, concluiu que a menor intensidade de corte proporcionou maior produção de forragem, com maior percentual de folhas e menor perda por senescência, e com o impacto da adubação utilizada, pode-se reduzir o intervalo de corte, e destacou as forrageiras capim mulato e capim-xaraés com potencial para sistemas intensivos.

Casagrande (2007) ao considerar as avaliações de características morfogênicas e estruturais do dossel, concluiu que a oferta de forragem ao 
FREIRIA, L.B. et al. Impacto da adubação nitrogenada nas características morfofisiológicas de gramíneas do gênero Brachiaria e Cynodon em pastejo e corte. PUBVET, Londrina, V. 8, N. 8, Ed. 257, Art. 1706, Abril, 2014.

redor de $8 \%$ do PV parece ser a mais indicada para o manejo de pastagem de Brachiaria brizantha cv. Marandu em sistema de pastejo intermitente.

Da Silva et al. (2012) ao avaliar morfogênese e estrutura do dossel, recomenda para Brachiaria decumbens a altura de resíduo $25 \mathrm{~cm}$ combinada com a altura de corte $40 \mathrm{~cm}$, junto à aplicação de $100 \mathrm{~kg} / \mathrm{ha}$ de $\mathrm{N}$, promovem maior produção de matéria seca total em menor espaço de tempo (28 dias), permitindo maiores taxas de lotação e facilitando o manejo no sistema de lotação rotacionada.

Carlotoet al. (2011) ao avaliar o valor nutritivo, a estrutura do dossel, a

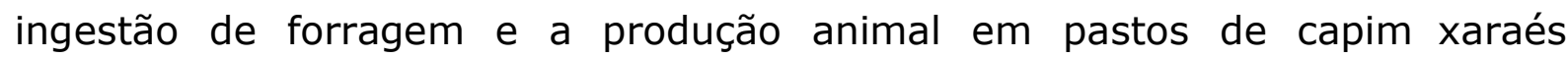
(Urochloa brizantha cv. Xaraés), manejados a 15, 30 e $45 \mathrm{~cm}$ de altura, sob lotação contínua, durante o período das águas, com adução de $100 \mathrm{~kg} / \mathrm{ha}$ de $\mathrm{N}$, puderam notar que nas alturas de 30 e $45 \mathrm{~cm}$ houve uma maior produção de matéria seca total (6.319 e $8.062 \mathrm{~kg} / \mathrm{ha})$ e de matéria seca de lamina foliar ( 2.159 e $2176 \mathrm{~kg} / \mathrm{ha}$ ) em relação a altura de $15 \mathrm{~cm}$ (MST, $2.991 \mathrm{~kg} / \mathrm{ha}$; MSLF, $1.231 \mathrm{~kg} / \mathrm{ha}$ ). Mas a altura de $15 \mathrm{~cm}$ permitiu uma maior percentagem de lamina foliar e menor percentagem de colmo, ou seja, maior valor nutritivo, o que possibilitou um ganho semelhante por animal (730 g em todas as alturas manejas) e ainda um ganho por área maior para o pasto manejado com $15 \mathrm{~cm}$ (678 kg/ha), em comparação ao com 45 cm (324 kg/ha), já o manejado com $30 \mathrm{~cm}$ foi semelhante às outras alturas. A altura de $30 \mathrm{~cm}$ apresenta menor influência de condições ambientais adversas, e o capim xaraés pode ser manejo na altura de 15 a $30 \mathrm{~cm}$ em lotação contínua, no períodos das águas (Tabela 1).

Flores et al. (2008) ao avaliarem a produção de forragem, as características estruturais, a ingestão de forragem, o comportamento de ingestão e o desempenho animal de bovinos em pastos de capins marandu e xaraés submetidos a três intensidades de pastejo $(15,30,40 \mathrm{~cm})$ em lotação contínua, com adubação de manutenção de $200 \mathrm{~kg} / \mathrm{ha}$ do formulado 0-20-20 e $90 \mathrm{~kg}$ de nitrogênio/ha, concluíram a seguinte recomendação para o capimmarandu, deve ser manejado entre 25 e $40 \mathrm{~cm}$ de altura e para o capim- 
FREIRIA, L.B. et al. Impacto da adubação nitrogenada nas características morfofisiológicas de gramíneas do gênero Brachiaria e Cynodon em pastejo e corte. PUBVET, Londrina, V. 8, N. 8, Ed. 257, Art. 1706, Abril, 2014.

xaraés a $40 \mathrm{~cm}$, compreendendo as estações de verão (janeiro, fevereiro e março) e outono (abril, maio e junho).

Tabela 1 -Média e nível de probabilidade (p) para as variáveis avaliadas em

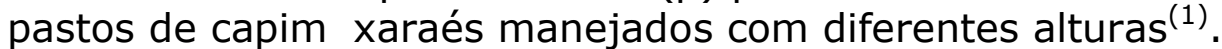

\begin{tabular}{lcccc}
\hline Variáveis $^{(2)}$ & \multicolumn{3}{c}{ altura } & P \\
\cline { 2 - 4 } & 15 & 20 & 25 & \\
\hline MST (kg/ha de MS & $2.991 \mathrm{c}$ & $6.319 \mathrm{~b}$ & $8.062 \mathrm{a}$ & 0,0001 \\
MSLF (kg/ha de MS) & $1.231 \mathrm{~b}$ & $2.159 \mathrm{a}$ & $2176 \mathrm{a}$ & 0,0003 \\
PF\% & $40,30 \mathrm{a}$ & $34,10 \mathrm{~b}$ & $26,8 \mathrm{c}$ & 0,0001 \\
PC & $23,30 \mathrm{~b}$ & $32,90 \mathrm{a}$ & $33,10 \mathrm{a}$ & 0,0002 \\
RFC & $1,78 \mathrm{a}$ & $1,06 \mathrm{~b}$ & $0,84 \mathrm{~b}$ & 0,0001 \\
TL & $3,5 \mathrm{a}$ & $2,5 \mathrm{~b}$ & $2,00 \mathrm{~b}$ & 0,0029 \\
DIVMO (\%) & $62,00 \mathrm{a}$ & $58,40 \mathrm{ab}$ & $57,40 \mathrm{~b}$ & 0,0270 \\
CMS (kg de MS / 100 kg de & $1,89 \mathrm{~b}$ & $2,26 \mathrm{a}$ & $2,34 \mathrm{a}$ & 0,0324 \\
PV) (kg de MS / 100 kg de & $1,89 \mathrm{a}$ & $2,28 \mathrm{~b}$ & $2,34 \mathrm{a}$ & 0,0245 \\
IMS (kV) & & & & \\
PV) & 0,81 & 0,76 & 0,61 & 0,0622 \\
GMD (KG) & $678 \mathrm{a}$ & $499 \mathrm{ab}$ & $324 \mathrm{~b}$ & 0,0443 \\
\hline GPA (kg ha ${ }^{-1}$. período) & &
\end{tabular}

(1)Médias sequidas por letras iguais não diferem entre si pelo teste de Tukey, a 5\% de probabilidade. (2)Produção de massa de matéria seca (MST) e de lâmina foliar (MSLF), percentagem de lâmina foliar (PF) e de colmo (PC), relações folha:colmo (RFC), taxa de lotação (TL), teores de digestibilidade in vitro da matéria orgânica (DIVMO) das amostras de simulação do pastejo, e consumo de matéria seca (CMS) pelos animais, ingestão de matéria seca (IMS), ganho médio diário (GMD), e ganho de peso vivo por área (GPA).

Santoset al. (2011) ao avaliar o perfilhamento às estratégias adequadas de manejo ( $25 \mathrm{~cm}$ período todo, $15 \mathrm{~cm}$ no inverno e $25 \mathrm{~cm}$ na primavera e verão) nas estações do ano (inverno, primavera e verão) da Brachiaria decumbens cv. Basilisk em lotação contínua com bovinos, com aplicação de $100 \mathrm{~kg} \mathrm{ha}^{-1}$ de $\mathrm{N}$ e $\mathrm{K}_{2} \mathrm{O}$, bem como $25 \mathrm{~kg} \mathrm{ha}^{-1}$ de $\mathrm{P}_{2} \mathrm{O}_{5}$, usando o formulado 205-20, puderam concluir que tão somente os manejos estratégicos do pasto influenciam nessa variável, mas como também a estações do ano foram significativas, desta forma, fizeram a seguinte orientação em lotação contínua, o rebaixamento da $B$. decumbens para $15 \mathrm{~cm}$ no inverno e sua manutenção em $25 \mathrm{~cm}$ na primavera e verão otimizam sua renovação de perfilhos, e é vantajoso, quando comparado à manutenção do pasto com altura fixa de 25 cm durante as estações, salvo a importância da adubação quando se pretende em realizar uma maior intensidade de pastejo. 
FREIRIA, L.B. et al. Impacto da adubação nitrogenada nas características morfofisiológicas de gramíneas do gênero Brachiaria e Cynodon em pastejo e corte. PUBVET, Londrina, V. 8, N. 8, Ed. 257, Art. 1706, Abril, 2014.

Em síntese, as recomendações para o gênero Brachiaria, em atenção às características morfofisiológicas com otimização do uso da forragem, uma adubação nitrogenda de $50 \mathrm{~kg}$ corte- ${ }^{1}$ ou $50 \mathrm{~kg} / \mathrm{ha} / \mathrm{ano}$, com adubação de manutenção de fosfato de $100 \mathrm{~kg} / \mathrm{ha} / \mathrm{ano}$ e potássica de $50 \mathrm{~kg} / \mathrm{ha} / \mathrm{ano}$, não descartando a análise do solo. Mas essas recomendações podem variar de acordo com sistema impregado, em função dositema de lotação, intermintente, altura de pré-corte (35 a $40 \mathrm{~cm}$ ), intesidade de corte (15 a $20 \mathrm{~cm}$ do solo), intervalo de corte (35 a 40 dias), e altura do dossel em lotação contínua com maior amplitude (25 à $40 \mathrm{~cm}$ ), sofrendo influencias do impacto da adubação e climaticas. Diante das recomendações, sempre se atentar as particularidades dos cultivares do gênero.

\section{Gênero Cynodon}

Os processos de formação e desenvolvimento de folhas são fundamentais para o crescimento vegetal, dado o papel destas na fotossíntese, ponto de partida para a formação de novos tecidos (FAGUNDES et al., 2012). O conhecimento dessas características morfofisiológicas das gramíneas forrageiras representa o ponto de partida para o entendimento básico das respostas das plantas ao corte ou pastejo. Em função disto, torna-se indispensável o correto e aprofundado estudo das características morfogênicas e estruturais de forma integrada e diferenciada para as principais gramíneas forrageiras de interesse econômico (ZANINE, 2005).

Aliado a esse estudo, a adoção da técnica de adubação de pastagem com fertilizante nitrogenado, se tornar outra importante estratégia para o manejo de pastagem, principalmente em respostas morfofisiológicas, porque aumenta a densidade populacional de perfilhos que e determinante da perenidade do pasto (FAGUNDESet al., 2012).

Dentro do grupo de gramíneas estudadas, as do gênero Cynodon são capazes de produzir grandes quantidades de matéria seca, com boa relação folha/colmo, resultando em um adequado valor nutritivo, o que se fazem 
FREIRIA, L.B. et al. Impacto da adubação nitrogenada nas características morfofisiológicas de gramíneas do gênero Brachiaria e Cynodon em pastejo e corte. PUBVET, Londrina, V. 8, N. 8, Ed. 257, Art. 1706, Abril, 2014.

apropriadas para alimentar animais de alta produção, tanto sob a forma de pasto ou feno (GONÇALVES et al. (2002). Nas condições brasileiras as gramíneas do gênero Cynodontêm sido empregadas principalmente na bovinocultura de leite e também para produção de forragem conservada e, em menor escala utilizada para animais de produção de carne (VILELA et al., 2002). Desta forma, logo, é apresentado a taxa de aparecimento e alongamento foliar, filocrono (morfogênicas) e produção de matéria seca, densidade populacional de perfilhos e taxa de senescência foliar (estruturais) em resposta adubação e pastejo.

\subsection{Taxa de alongamento de foliar}

Premazziet al. (2011) ao verificarem a influência de doses (0, 80, 160 e $240 \mathrm{mg} / \mathrm{kg}$ de solo) e épocas de aplicação de nitrogênio após o corte (imediatamente após o corte e sete dias após o corte das plantas) no fator de correção de área foliar, na taxa de alongamento de folhas (TAIF) e no comprimento e área da lâmina foliar (CLF e AF) do capim-bermuda tifton 85 (Cynodonspp), experimento conduzido em casa de vegetação, observaram um efeito quadrático positivo com o aumento das doses de nitrogênio para TAlF, CLF e AF.

Pereira et al. (2011) também encontraram o aumento na taxa de alongamento foliar com a adubação nitrogenada, chegando a valores próximos de $20 \mathrm{~mm} /$ perfilho/dia com a maior dose (133 kg/ha). Da Silva et al. (2012) confirmam que adubação aumenta a TAIF. Vilela et al (2005) encontra valores que variam entre 23,43 à $31,27 \mathrm{~mm} /$ perfilho/dia, com $200 \mathrm{~kg} / \mathrm{ha} /$ ano de $\mathrm{N}$, em pastejo de lotação rotacionada.

Bezerra (2011) ao avaliar as características morfogênicas e o acúmulo de forragem do capim-tifton 85 manejado sob três períodos de descanso $(4,5$; 6,$5 ; 8,5 \mathrm{n}^{\circ}$ de folhas/perfilho) e dois resíduos pós-pastejo (10 e $5 \mathrm{~cm}$ ) em diferentes ciclos de pastejo, com adubações fixadas de $120 \mathrm{~kg} / \mathrm{ha}$ de $\mathrm{P}_{2} \mathrm{O}_{5}, 100$ $\mathrm{kg} / \mathrm{ha}$ de $\mathrm{K}_{2} \mathrm{O}$ e $600 \mathrm{~kg} / \mathrm{ha}$ de $\mathrm{N}$, puderam notar que a TAlF variou em função 
FREIRIA, L.B. et al. Impacto da adubação nitrogenada nas características morfofisiológicas de gramíneas do gênero Brachiaria e Cynodon em pastejo e corte. PUBVET, Londrina, V. 8, N. 8, Ed. 257, Art. 1706, Abril, 2014.

do período de descanso e resíduos de pastejo, para os período de descanso valores de 3,$04 ; 2,23$ e 1,79 cm/perf $x$ dia, maior PD com menor TAlF devido avanço da maturidade do capim, ocorreu maior competição por fotoassimilados, para os resíduos de pós - pastejo valores de 2,51 e 2,19 $\mathrm{cm} /$ perf $x$ dia, menor RPP com menor TAIF, devido pastejo mais intenso promover um habito de crescimento mais prostrado do capim, o que ocasiona um maior sombreamento e menor alongamento foliar.

\subsection{Taxa de aparecimento foliar}

Pereira et al. (2011) ao avaliarem as características morfogênicas estruturais do capim-tifton 85 adubado com nitrogênio nas doses de 0, 33, 66, 100 ou $133 \mathrm{~kg} / \mathrm{ha} /$ ano em três alturas à data de corte $(30,40$ ou $50 \mathrm{~cm})$, para taxa de aparecimento foliar a altura da planta influenciou de forma negativa $(0,35 ; 0,28 ; 0,21$ folha/ perfilho/dia, respectivamente as alturas) , ou seja para cada centímetro de aumento na altura da planta por ocasião do corte, registraram-se decréscimos de 0,0667 folha/ perfilho/dia. E a cada quilo de nitrogênio aplicado aumentou 0,0024 folha/perfilho/dia, com doses de $\mathrm{N}$ máxima de $133 \mathrm{~kg} / \mathrm{ha} / \mathrm{ano}$, valores de 0,66; 0,60 e 0,53 folha/perfilho/dia, respectivamente as altura de corte. $\mathrm{Na}$ figura 4, apresenta o gráfico e a equação gerada.

Oliveira et al. (2000) ao avaliarem a dinâmica do aparecimento do capimbermuda 'Tifton 85' (Cynodonspp.) colhido aos 14, 21, 28, 35, 42, 49, 56, 63 e 70 dias de rebrota, com adubação nitrogenada de $75 \mathrm{~kg} / \mathrm{ha}$ e $60 \mathrm{~kg} / \mathrm{ha}$ de $\mathrm{K}_{2} \mathrm{O}$, observaram que a taxa de aparecimento de folhas individuais decresceu linearmente durante o desenvolvimento da planta, estimou-se valores de 0,62 e 0,23 folhas/dia aos 14 e 70 dias de rebrota, respectivamente. Bezerra (2011) encontrou redução nos valores $\operatorname{TApF}(0,25 ; 0,21$ e 0,16 folha/dia) com o aumento do período de descanso $\left(4,5 ; 6,5 ; 8,5 \mathrm{n}^{\circ}\right.$ de folhas/perfilho), redução associada ao maior comprimento da bainha em níveis de inserção cada vez mais altos. 
FREIRIA, L.B. et al. Impacto da adubação nitrogenada nas características morfofisiológicas de gramíneas do gênero Brachiaria e Cynodon em pastejo e corte. PUBVET, Londrina, V. 8, N. 8, Ed. 257, Art. 1706, Abril, 2014.

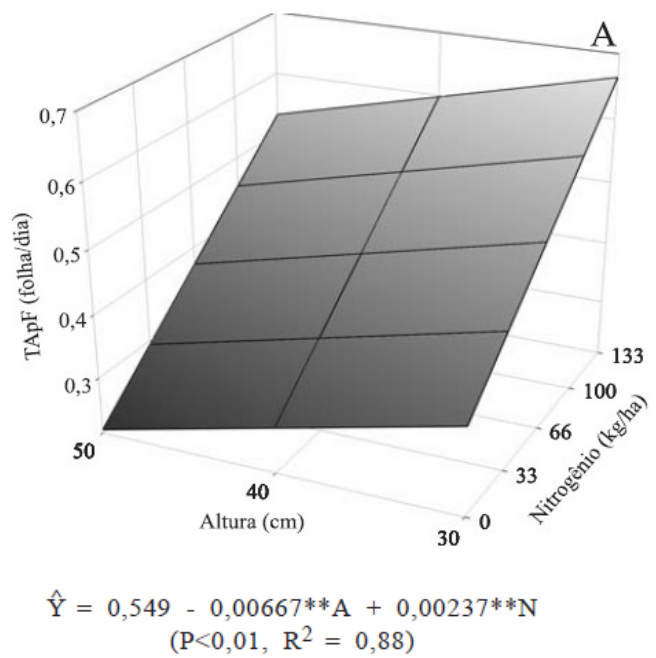

Figura 4: Taxa de aparecimento foliar (TApF) do capim-tifton 85 em função da dose de nitrogênio (N) e da altura da planta $(A)$. Fonte: Pereira et al. (2011)

Vilela et al. (2005) ao estimarem as características morfogênicas e estruturais e a taxa de acúmulo de matéria seca (MS) de lâminas foliares em uma pastagem de Cynodondactyloncv. coastcross, manejada em sistema de lotação rotacionada com vacas em lactação, com um dia de ocupação e entre 27 e 30 dias de ocupação, com adubação de 200 kg/ha/ano de N, 200 $\mathrm{kg} / \mathrm{ha} / \mathrm{ano}$ de $\mathrm{K}_{2} \mathrm{O}$ e $50 \mathrm{~kg} / \mathrm{ha} / \mathrm{ano}$ de $\mathrm{P}_{2} \mathrm{O}_{5}$, apresentaram uma TApF variando entre 0,24 e 0,33 folha/dia no decorrer do ano.

\subsection{Filocrono}

Pereira et al. (2011) observaram para valores de filocrono (período entre o aparecimento de duas folhas consecutivas em um mesmo perfilho) um aumento com maior altura da planta (para cada incremento de $1 \mathrm{~cm}$ na altura da planta ao corte, o filocrono aumentou 0,04 e 0,01 dia no primeiro e segundo ano) e uma redução com o aumento da adubação nitrogenada(redução de 0,015 e 0,010 unidade de filocrono para cada 
FREIRIA, L.B. et al. Impacto da adubação nitrogenada nas características morfofisiológicas de gramíneas do gênero Brachiaria e Cynodon em pastejo e corte. PUBVET, Londrina, V. 8, N. 8, Ed. 257, Art. 1706, Abril, 2014.

quilograma de nitrogênio aplicado no primeiro e segundo ano). O demostra que está forrageira tem grande resposta a adubação. Oliveira et al. (2000) encontram um aumento do filocrono com aumento do tempo de rebrotação de 14 para 70 dias (1,44 a 4,10 dias perfilho).

\subsection{Taxa de senescência foliar}

Pereira et al. (2011) para taxa de senescência foliar (TSeF), valores médios foram maiores com o aumento da altura do pasto, definiram que a cada acréscimo de um centímetro na altura das plantas por ocasião dos cortes, a TSeF aumentou 0,30 mm/perfilho.dia. Oliveira et al (2000) também encontraram aumento na taxa de senescência foliar $(0,24$ a 12,24 $\mathrm{mm} /$ dia.perfilho) com o aumento de dias de rebrota (14 a 70 dias). Bezerra (2011) confirmou que o aumento do período de descanso $\left(4,5 ; 6,5 ; 8,5 \mathrm{n}^{\circ}\right.$ de folhas/perfilho) provocou aumento na TST $(0,34 ; 0,54$ e 0,72 cm/perf $x$ dia). Vilela et al. (2005) observaram taxa de senescência de 2,49 mm/dia, aos 24 dias de descanso, somente no período da primavera.

Oliveira et al. (2000) para número de folhas vivas por perfilho (NFVP), observou-se resposta cúbica, registrando-se valor máximo de 9,5 folhas verdes por perfilho aos 28 dias, que se manteve estável até os 35 dias e, posteriormente, reduziu para 8,2 folhas vivas por perfilho aos 56 dias (figura 5). Ou seja, após a nona folha, começa inicializar o período de senescência foliar. Bezerra (2011) observou o aumento de NFVP até 8,5 folhas por perfilho. 
FREIRIA, L.B. et al. Impacto da adubação nitrogenada nas características morfofisiológicas de gramíneas do gênero Brachiaria e Cynodon em pastejo e corte. PUBVET, Londrina, V. 8, N. 8, Ed. 257, Art. 1706, Abril, 2014.

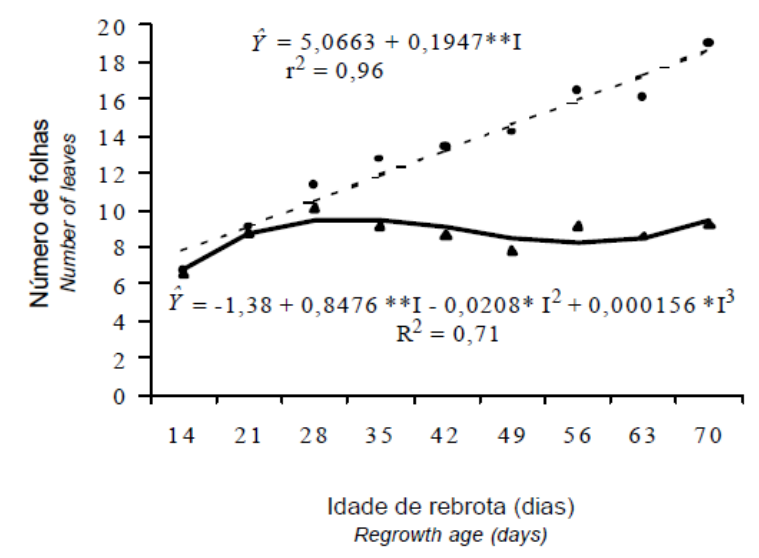

Figura 5: Estimativa do número total de folhas (- - ) e de folhas vivas (_ $($ ) expandidas por perfilho da grama-bermuda. Tifton 85 , em diferentes idades de rebrota (I).

\subsection{Densidade populacional de perfilhos}

Fagundes et al. (2011) ao avaliarem a densidade populacional de perfilhos, biomassa e densidade volumétrica de forragem, o desempenho de ovinos e a taxa de lotação em pastos de capim-tifton 85 adubados com doses crescentes de nitrogênio $(0,100,200$ e $400 \mathrm{~kg} / \mathrm{ha} / \mathrm{ano})$, submetidos ao regime de lotação contínua, a altura média da pastagem mantida em torno de $10 \mathrm{~cm}$, no períodos das águas, concluíram a adubação nitrogenada em pastos de capim-tifton 85 promove aumento na quantidade de massa de forragem (máx. $4.776 \mathrm{~kg} / \mathrm{ha}$ de $\mathrm{MS}$ ), na densidade populacional de perfilhos (max. 3.132 perfilho/ $/ \mathrm{m}^{2}$ ) e na densidade volumétrica da forragem (max. $478 \mathrm{~kg} / \mathrm{cm}$. ha de MS), possibilitando alto desempenho animal quando utilizado em pastejo contínuo com ovinos. Vilela et al. (2005) encontrou valores de entre 2.428 à $3.021 \mathrm{n}^{0}$ de perfilhos $/ \mathrm{m}^{2}$, com $200 \mathrm{~kg} / \mathrm{ha} / \mathrm{ano}$ de $\mathrm{N}$, com altura de resíduo de $20 \mathrm{~cm}$ (capim-coastcross).

Alvim et al. (1999) ressalta que a persistência de uma gramínea pode ser comprometida com a ausência de adubação nitrogenada (deve ser acima de 
FREIRIA, L.B. et al. Impacto da adubação nitrogenada nas características morfofisiológicas de gramíneas do gênero Brachiaria e Cynodon em pastejo e corte. PUBVET, Londrina, V. 8, N. 8, Ed. 257, Art. 1706, Abril, 2014.

$100 \mathrm{~kg} / \mathrm{ha} / \mathrm{ano}$ ) e pelo menor intervalo de cortes ( 2 semanas nas chuvas e 4 semanas na seca).

\subsection{Produção de matéria seca}

Rocha et al. (2002) ao avaliarem produção de matéria seca e de proteína bruta e os teores de proteína bruta, fibra em detergente neutro e fibra em detergente ácido nos capins Coastcross, Tifton 68 e Tifton 85, submetidos a quatro doses de nitrogênio: 0, 100, 200 e $400 \mathrm{~kg} / \mathrm{ha}$, na forma de sulfato de amônio, com altura de corte de $10 \mathrm{~cm}$ e intervalo de 42 dias, na época das águas, observaram um incremento produção de matéria seca (PMS) de 0,01580 t para cada $\mathrm{kg}$ de nitrogênio aplicado, e ao atingir $200 \mathrm{~kg} / \mathrm{ha}$ de $\mathrm{N} \mathrm{a}$ PMS variou entre os cultivares de 9,10 a 9,62 t/ha (Coastcross e Tifton 85, respectivamente), ou seja, a adubação nitrogenada incrementa a PMS.

Cecatoet al. (2001b) ao avaliarem cultivares do gênero Cynodon(tifton 85 e coastcross) com e sem adubação nitrogenada ( 0 e $400 \mathrm{~kg} / \mathrm{ha}$ ), em dois períodos estacionais com altura de corte de $10 \mathrm{~cm}$ com distintas tempos de rebrotação (verão, 35 dias e inverno, 70 dias), com adubações fixadas de potássio (após cortes a $2 \%$ da PMS) e fósforo $(120 \mathrm{~kg} / \mathrm{ha}$ ), a produção de matéria seca verde total foi incrementada com adubação nitrogenada nos diferentes períodos, com produções de 7,46 a 14,25 ton/ha para o tifton 85 e 5,33 a 12,12 ton/ha do coastcross, no verão, e no inverno com produções de 1,92 a 2,37 ton/ha para o capim tifton 85 e 1,79 a 2,73 ton/ha para o capim coastcross. A diferença de produção entre os períodos está ligada a fatores climáticos (baixa umidade e temperatura, diminuição do fotoperíodo).

Cecatoet al. (2001) ao avaliarem os teores de carboidratos nãoestruturais ( $\mathrm{CHO}$ ), nitrogênio total (NT) e produção de raízes em pastagem de Coastcross-1 (Cynodondactylon(L.) Pers), em quatro níveis de resíduo de matéria seca (RMS: 1978, 2130, 2545 e 3857 kg de MS/ha), sob pastejo contínuo e lotação variável, com adubação nitrogenada (200 kg de N/ha) fracionada em quatro aplicações, encontraram resultados para os teores de 
FREIRIA, L.B. et al. Impacto da adubação nitrogenada nas características morfofisiológicas de gramíneas do gênero Brachiaria e Cynodon em pastejo e corte. PUBVET, Londrina, V. 8, N. 8, Ed. 257, Art. 1706, Abril, 2014.

carboidratos não-estruturais nas raízes e para nitrogênio total na base de colmo não foram influenciados pelos níveis de RMS, no entanto a produção de matéria seca de raízes aumentou, à medida que se elevaram os RMS, concluindo que o nível de resíduo de matéria seca superior a $2545 \mathrm{~kg} / \mathrm{MS} / \mathrm{ha}$ é o mais recomendado para manter adequado o nível desses elementos responsáveis pela manutenção do crescimento, pela rebrota efetiva e elevada produção da pastagem.

\subsection{Recomendações}

Gonçalves et al. (2002) ao estimarem a produção de MS, relação lâmina/colmo e o valor nutritivo de três cultivares do gênero Cynodon(Coastcross, Tifton 44 e Tifton 85) colhidos com a idade de 21, 42 e 63 dias, na primavera e no verão, 42, 63 e 84 dias, no outono e 63 e 84 dias, no inverno, puderam notar que a produção de MS incrementou com o aumento dos dias da colheita, já a relação lâmina/colmo (L/C), o teor de proteína bruta $(\mathrm{PB})$, a energia metabolizável (EM) estimada e a digestibilidade in vitro da matéria seca (DIVMS) e da matéria orgânica (DIVMO) foram afetadas negativamente à medida em que aumentou-se a idade de colheita, desta forma, recomendam que as colheitas sejam realizadas entre 21 e 42 dias, para não reduzir o valor nutritivo da planta.

Pereira et al. (2011) concluíram que na condição de desfolhação intermitente, o capim-tifton 85 deve ser colhido com altura de até $30 \mathrm{~cm}$. Oliveira et al. (2000), concluíram que o capim-tifton 85 teve melhores características (morfofisiológicas) com tempo de descanso entre 28 e 35 dias, no período das águas. Para Vilela et al. (2005) tempo de descanso de 28 dias (capim-coastcross).

Segundo Primavesiet al. (2004) para capim-coastcross, com corte de 10 $\mathrm{cm}$, recomenda-se adubações nitrogenadas de 50 e 50 a $100 \mathrm{~kg}^{-1} \mathrm{ha}^{-1} \mathrm{corte}^{-1}$, respectivamente, para nitrato de amônio e uréia, com manutenção de $60 \mathrm{~kg}$ $\mathrm{ha}^{-1}$ de $\mathrm{K}_{2} \mathrm{O}$ e $100 \mathrm{~kg} \mathrm{ha}^{-1}$ de $\mathrm{P}_{2} \mathrm{O}_{5}$. Bezerra (2011) com melhores respostas do 
FREIRIA, L.B. et al. Impacto da adubação nitrogenada nas características morfofisiológicas de gramíneas do gênero Brachiaria e Cynodon em pastejo e corte. PUBVET, Londrina, V. 8, N. 8, Ed. 257, Art. 1706, Abril, 2014.

capim tifton, se utilizou adubação nitrogenada de 75 a $85 \mathrm{~kg} / \mathrm{ha} /$ corte (uréia), e $120 \mathrm{~kg} / \mathrm{ha}$ de $\mathrm{P}_{2} \mathrm{O}_{5}$ e $100 \mathrm{~kg} / \mathrm{ha}$ de $\mathrm{K}_{2} \mathrm{O}$, com período de descanso de 30 dias, com altura de corte de 10 e $5 \mathrm{~cm}$, sendo a menor altura utilizada a maior dose de nitrogênio.

Com as informações geradas, as gramíneas do gênero Cynodon, que possui um comportamento de crescimento prostrado, mostrou-se ter grandes respostas a adubação, principalmente nitrogenadas, com melhor aproveitamento do pasto utilizando $200 \mathrm{~kg} / \mathrm{ha}$ ou $50 \mathrm{~kg} / \mathrm{ha}$ /corte de $\mathrm{N}$, o que Ihe confere um pastejo com altura de corte de $10 \mathrm{~cm}$, condizendo com 28 a 30 dias de descanso, lotação intermitente, nas águas, e na seca um período maior de descanso, acima de 42 dias (taxa de lotação pode variar entre 7 à 8 UA/ha).

Em lotação contínua, manter o pasto a uma altura de 10 a $20 \mathrm{~cm}$, variando conforme os intemperes climáticos, com taxa de lotação variável (1,5 a 2 UA/ha). Essas recomendações visão uma melhor acomodação do pasto em respeito às características morfofisiológicas e também uma melhor resposta animal. Entre os cultivares, pode haver uma pequena variação, pois o capimtifton 85, nessas condições apresenta uma maior produção que o capimcoastcross, o que permite um melhor desfrute da área.

\section{Considerações finais}

Ao considerar o conhecimento das características morfofisiológicas de gramíneas do gênero Brachiaria e Cynodon, pode se constatar que juntamente com o pastejo e corte, a adubação do pasto mostra-se uma pratica de grande auxilio para que tenha uma boa utilização da forragem sem prejudicar sua perenidade. Sendo assim, torna-se necessário um maior entendimento de como essas ferramentas poderão ser usadas de forma combinada no dia-a-dia da propriedade rural. 


\section{Referencias bibliográficas}

ALENCAR, C. A. B. de; Cóser, A. C.; MARTINS, C .E.; OliVEIRA, R. A. de; CECON, P. R.; LEAL, B. G.; FIGUEIREDO, J. L. A.; CUNHA, F. F. da.Doses de nitrogênio e estações do ano afetando a composição bromatológica e digestibilidade de capins cultivados sob pastejo. Revista Ceres, v. 56, n.5, p. 640-647, 2009.

ALEXANDRINO, E.; NASCIMENTO JR., D. do; MOSQUIM, P. R.; REGAZZI, A. J.; ROCHA, F. C. Características Morfogênicas e Estruturais na Rebrotação da Brachiaria brizantha cv. Marandu Submetida a Três Doses de Nitrogênio. Revista Brasileira de Zootecnia, v.33, n.6, p.13721379, 2004.

ALEXANDRINO, E.; NASCIMENTO JR., D. do; REGAZZI, A. J.; ROCHA, F. C.; MOSQUIM, P. R.; SOUZA, D. de P. Características morfogênicas e estruturais da Brachiaria brizantha cv. Marandu submetida a diferentes doses de nitrogênio e frequências de cortes. Acta Scientiarum, v. 27, no. 1, p. 17-24, 2005.

ALVeS, J. de S.; Piers, A. J. V.; MATSUMoto, S. N.; Figueiredo, M. P. de; Ribeiro, G. S. Características morfológicas e estruturais da Brachiaria decumbens stapf. submetida a diferentes doses de nitrogênio e volumes de água. Acta VeterinariaBrasilica, v.2, n.1, p.1$10,2008$.

ALVES, J.S., PIRES, A.J.V., MATSUMOTO, S.N., FIGUEIREDO, M.P. E RIBEIRO, G.S. Características morfológicas e estruturais da Brachiaria decumbens Stapf. submetida a diferentes doses de nitrogênio e volumes de água. Acta VeterinairaBrasilica, v. 2, n. 1, p.1$10,2008$.

ALVIM, M. J.; XAVIER, D. F.; VERNEQUE, R. da S.; BOTREL, M. de A. resposta do tifton 85 a doses de nitrogênio e intervalos de cortes. Pesquisa Agropecuária Brasileira, v.34, n.12, p.2345-2352, 1999.

ANDRADE, A. C.; ROdRigueS, B. H. N.; MAGAlHÃES, J. A.; CECON, P. R.; MendeS, F. M. A. Adubação nitrogenada e irrigação dos capins Tangola (Brachiaria spp.) e Digitaria (Digitaria sp): massa de forragem e recuperação de nitrogênio. Revista Científica de Produção Animal, v.11, n.1, p.1-14, 2009.

ARAÚJO, F. F. de; TIRITAN, C. S.; OLIVEIRA, T. R. de. Compostos orgânicos semicurados na adubação de pastagem degradada de Brachiaria decumbens. Revista Ciência Agronômica, v. 40 , n. 1, p. $1-6,2009$.

BAUER, M. de O.; PACHECO, L. P. A.; CHICHORRO, J. F.; VASCONCELOS, L. V.; PEREIRA, D. F. C. Produção e características estruturais de cinco forrageiras do gênero Brachiaria sob intensidades de cortes intermitentes. Ciência Animal Brasileira, v. 12, n. 1, p. 17-25, 2011.

BEZERRA, A. P. A. Morfofisiologia do dossel e desempenho de ovinos em capim-tifton 85. Fortaleza, CE, UFC, 2011. 174p. Tese (Doutora em Zotecnia) Universidade Federal do Ceará, 2011.

BODDEY, R.M.; MACEDO, R.; TARRÉ, R.M.; FERREIRA, E.; OLIVEIRA, O.C. de; REZENDE, C. de P.; CANTARUTTI, R.B.; PEREIRA, J.M.;ALVES, B.J.R.; URQUIAGA, S. Nitrogencycling in Brachiaria pastures: thekeytounderstandingtheprocessofpasture decline. Agriculture, EcosystemsandEnvironment, v.103, p.389-403, 2004. 
CARARD, M.; NERES, M. A.; TONELLO, C. L. Efeito de doses crescentes de nitrogênio no desenvolvimento de cultivares de Brachiaria brizantha. Revista da FZVA, v.15, n.2, p.135$144,2008$.

CARLOTO, M. N.; EUCIDES, V. P. B.; MONTAGNER, D. B.; LEMPP, B.; DIFANTE, G. dos S.; PAULA, C. C. L. de. Desempenho animal e características de pasto de capim国araessob diferentes intensidades de pastejo, durante o período das águas. Pesquisa Agropecuária Brasileira, v.46, n.1, p.97-104, 2011.

CASAGRANDE, D. R. Características morfogênicas do dossel de Brachiaria brizantha (hochst ex. a. rich.) cv. marandu manejada com diferentes ofertas de forragem sob lotação intermitente. Jabuticabal, SP. Unesp, 2007. 85p. Dissertação (Mestre em Zootecnia) Faculdade de Ciências Agrárias e Veterinárias - Unesp. 2007.

CATAGNARA, D. D. ZOZ, T.; KRUTZMANN, A.; UHLEIN, A.; MESQUITA, E. E.; NERES, M. A.; OLIVEIRA, P. S. R. de. Produção de forragem, características estruturais e eficiência de utilização do nitrogênio em forrageiras tropicais sob adubação nitrogenada. Revista Semina: Ciências Agrárias, v. 32, n. 4, p. 1637-1648, 2011.

CECATO, U.; YANAKA, F. Y.; BRITO FILHO, M. R. T. de; SANTOS, G. T. dos; CANTO, M. W. do; ONORATO, W. M.; PETERNELLI, M. Influência da adubação nitrogenada e fosfatada na produção, na rebrota e no perfilhamento do capim-marandu (Brachiaria brizantha [Hochst] Stapf. cv. Marandu). Acta Scientiarum, v. 22, n. 3, p.817-822, 2000.

CECATO, U.; CANO, C. C. P.; BORTOLO, M.; HERLING, V. R.; CANTO, M. W. do; CASTRO, C. R. de $C$. Teores de carboidratos não-estruturais, nitrogênio total e peso de raízes em Coastcross1 (Cynodondactylon(I.) pers) pastejado por ovinos. Revista Brasileira de Zootecnia, v. 30, n. 3, p. $644-650,2001$.

CECATO, U.; SANTOS, G. T. dos; MACHADO, M. de A.; GOMES, L. H.; DAMACENO, J. C.; JOBIM, C. C.; RIBAS, N. P.; MIRA, R. T.; CANO, C. C. P. Avaliação de cultivares do gênero Cynodoncom e sem nitrogênio. Acta Scientiarum, v. 23, n. 4, p. 781-788, 2001b.

DA SILVA, S. C. \& NASCIMENTO JR., D. do. Avanços na pesquisa com plantas forrageiras tropicais em pastagens: características morfofisiológicas e manejo do pastejo. Revista Brasileira de Zootecnia,v. 36, suplemento especial, p.121-138, 2007.

DA SILVA, T. C.; PERAZZO, A. F.; MACEDO, C. H. O.; BATISTA, E. D.; PINHO, R. M. A.; BEZERRA, H. F. C.; SANTOS, E. M. Morfogênese e estrutura de Brachiaria decumbens em resposta ao corte e adubação nitrogenada. Revista Archivos de Zootecnia, v. 61, n. 233, p.91-102, 2012.

DIFANTE, G. dos S.; NASCIMENTO JR., D. do; DA SILVA, S. C.; EUCLIDES, V. P. B.; MONTAGNER, D. B.; SILVEIRA, M. C. T. da; PENA, K. da S. Características morfogênicas e estruturais do capim-marandu submetido a combinações de alturas e intervalos de corte. Revista Brasileira de Zootecnia, v.40, n.5, p.955-963, 2011.

DIFANTE, G. dos S.; NASCIMENTO JR., D. do; DA SILVA, S. C.; EUCLIDES, V. P. B.; ZANINE, A. de M.; ADESE, B. Dinâmica do perfilhamento do capim-marandu cultivado em duas alturas e três intervalos de corte. Revista Brasileira de Zootecnia, v.37, n.2, p.189-196, 2008.

DOLEJAL, F. E. G.; ZANINI, F. H.; CASTAGNARA, D. D.; OLIVEIRA, P. S. R.; GONÇALVES JR., A. C. Produção de matéria seca da Brachiaria sp. cv. mulato sob adubação nitrogenada e potássica. Synergismusscyentifica, v.4, n. 1, 2009. 
EUClides, V. P. B.; CARDOSO, E. G.; MACEDO, M. C. M.; OliVeirA, M. P. de. Consumo voluntário de Brachiaria decumbens cv. basilisk e Brachiaria brizantha cv. marandu sob pastejo. Revista Brasileira de Zootecnia, v. 29, n. 6, p.2200-2208, 2000.

FAGUNDES, J. L.; FONSECA, D. M. de; GOMIDE, J. A.; NASCIMENTO JR., D. do; VITOR, C. M. T.; MORAIS, R. V. de; MISTURA, C.; REIS, G. de C.; MARTUSCELlO, J. A. Acúmulo de forragem em pastos de Brachiaria decumbens adubados com nitrogênio.Pesquisa Agropecuária Brasileira, v.40, n.4, p.397-403, 2005.

FAGUNDES, J. L.; MOREIRA, A. L.; FREITAS, A. W. de P.; ZONTA, A.; HENRICHS, R.; ROCHA, F. C.; BACKES, A. A.; VIEIRA, J S. Capacidade de suporte de pastagens de capim-tifton 85 adubado com nitrogênio manejadas em lotação contínua com ovinos. Revista Brasileira de Zootecnia, v.40, n.12, p.2651-2657, 2011.

FAGUNDES, J. L.; MOREIRA, A. L.; FREITAS, A. W. de P.; ZONTA, A.; HENRICHS, R.; ROCHA. Produção de forragem de Tifton 85 adubado com nitrogênio e submetido à lotação contínua. Revista Brasileira de Saúde e Produção Animal, v.13, n.2, p.306-317, 2012.

FLORES, R. S.; EUCLIDES, V. P. B.; ABRÃO, M. P. C.; GALBEIRO, S.; DIFANTE, G. dos S.; BARBOSA, R. A. Desempenho animal, produção de forragem e características estruturais dos capins marandu e xaraés submetidos a intensidades de pastejo. Revista Brasileira de Zootecnia, v.37, n.8, p.1355-1365, 2008.

GONÇALVEZ, G. D.; SANTOS, G. T. dos; CECATO, U.; JOBIM, C. C.; DAMASCENO, J. C.; BRANCO, A. F.; FARIA, K. P. Produção e valor nutritivo de gramíneas do gênero Cynodonem diferentes idades ao corte durante o ano. Acta Scientiarum, v. 24, n. 4, p. 1163-1174, 2002.

OliveirA, M. A. de; PEREIRA, O. G.; HUAMAN, C. A. M. y; GARCIA, R.; GOMIDE, J. A.; CECON, P. R.; SILVEIRA, P. R. da.Características morfogênicas e estruturais do capimbermuda 'tifton $85^{\prime}$ (Cynodonspp.) em diferentes idades de rebrota. Revista Brasileira de Zootecnia, v. 29, n. 6, p. 1939-1948, 2000.

LEMAIRE, G.; AGNUSDEI, M. Leaf tissue turnover and efficiency of herbage utilization. In: LEMAIRE, G.; HODGSON, J.; MORAES, A.; CARVALHO, P.C.F.; NABINGER, C. (Eds.). Grassland ecophysiology and grazing ecology. Wallingford: CABI, p.265-287, 2000.

LOPES, A.S.; WIETHOLTER, S.; GUILHERME, L.R. et al. Sistema plantio direto: bases para o manejo da fertilidade do solo. São Paulo: Associação Nacional para Difusão de Adubos, 2004. 115p.

MARANHÃO, C. M. de A.; SILVA, C. C. F. da; BONOMO, P.; PIRES, A. J. V. Produção e composição químico-bromatológica de duas cultivares de braquiária adubadas com nitrogênio e sua relação com o índice SPAD. ActaScientiarum, v. 31, n. 2, p. 117-122, 2009.

MATTHEW, C.; ASSUERO, S.G.; BLACK, C.K. Tiller dynamics of grazed swards. In: LEMAIRE, G.; HODGSON, J.; MORAES, A.; CARVALHO, P.C.F.; NABINGER, C. (Eds.). Grasslandecophysiologyandgrazingecology. Wallingford: CABI, p.127-150, 2000.

Medeiros, L. T.; PINTO, J. C.; CASTRO, E. M. de; REZENDE, A. V. de; LIMA, C. A. Nitrogênio e as características anatômicas, bromatológicas e agronômicas de cultivares de Brachiaria brizantha. Revista Ciência e Agrotecnologia, v. 35, n. 3, p. 598-605, 2011.

PATÊS, N. M. S. et al. Características morfogênicas e estruturais do capim-tanzânia submetido a doses de fósforo e nitrogênio.Revista Brasileira de Zootecnia, v.36, n.6, p.1736-1741, 2007. 
PENA, K. da SILVA. Perfilhamento em pastos de capim-mulato submetidos, a estratégias de pastejo rotativo. Viçosa, MG. UFV, 2010. 95p. Tese (Doutora em Zootecnia) Universidade Federal de Viçosa-UFV, 2010.

PENA, K. S. et al. Características morfogênicas, estruturais e acúmulo de forragem do capim tanzânia submetido a duas alturas e três intervalos de corte. Revista Brasileira de Zootecnia, v.38, n.11, p.2127-2136, 2009.

PEREIRA, O. G.; ROVETTA, R.; RIBEIRO, K. G.; SANTOS, M. E. R.; FONSECA, D. M. da; CECON, P. R. Características morfogênicas e estruturais do capim-tifton 85 sob doses de nitrogênio e alturas de corte. Revista Brasileira de Zootecnia, v.40, n.9, p.1870-1878, 2011.

PREMAZZI, L. M.; MONTEIRO, F. A.; OLIVEIRA, R. F. de. Crescimento de folhas do capimbermuda tifton 85 submetido à adubação nitrogenada após o corte. Revista Brasileira de Zootecnia, v.40, n.3, p.518-526, 2011.

PRIMAVESI, A. C.; PIMAVESI, O.; CORRÊA, L. de A.; CANTARELlA, H.; Silva, A. G. da; FREITAS, A. R. de; VIVALDI, L. J. Adubação nitrogenada em capim-coastcross: efeitos na extração de nutrientes e recuperação aparente do nitrogênio. Revista Brasileira de Zootecnia, v.33, n.1, p.68-78, 2004.

ROCHA, G. P.; ENVANGELISTA, A. R.; LIMA, J. A. de; ROSA, B. Adubação nitrogenada em gramíneas do gênero Cynodon. Revista Ciência Animal Brasileira, v. 3, n. 1, p. 1-9, 2002.

SANTOS Jr.; J. de D. G.; MONTEIRO, F. A.; LAVRES Jr.; J. Análise de Crescimento do CapimMarandu Submetido a Doses de Nitrogênio. Revista Brasileira de Zootecnia, v.33, n.6, p.1985-1991, 2004.

SANTOS, M. E. R.; GOMES, V. M.; FONSECA, D. M. da; ALBINO, R. L.; SILVA, S. P. da; SANTOS, A. L. Número de perfilhos do capim-braquiária em regime de lotação contínua. Acta Scientiarum, v. 33, n. 1, p. 1-7, 2011.

SILVA, C. C. F. da; BONOMO, P.; PIRES, A. J. V.; MARANHÃO, C. M. de A.; PATÊS, N. M. da SILVA; SANTOS, L. C. Características morfogênicas e estruturais de duas espécies de braquiária adubadas com diferentes doses de nitrogênio. Revista Brasileira de Zootecnia, v.38, n.4, p.657-661, 2009.

SOUSA, B. M. de L. Morfogênese e características estruturais dos capins andropógon e xaraés submetidos a três alturas de corte. Viçosa, MG. UFV, 2009. 132p. Dissertação (Mestre em Zootecnia) Universidade Federal de Viçosa-UFV, 2009.

SOUZA, I. A. de. Avaliação do capim-braquiária e dos atributos físicos do solo sob doses de nitrogênio. Diamantino, MG. UFVJM, 2012. 54p. Dissertação (Mestre em Zootecnia) Universidade Federal dos Vales do Jequitinhonha e Mucuri- UFVJM, 2012.

VILELA, D.; PAIVA, P. C. de A.; LIMA, J. A. de; CARDOSO, R. C. de. Morfogênese e acúmulo de forragem em pastagem de Cynodondactyloncv. coast-crossem diferentes estações de crescimento. Revista Brasileira de Zootecnia, v.34, n.6, p.1891-1896, 2005.

VILELA, D.; ALVIM, M. J.; MATOS, L. L. de; MATIOLLI, J. B. Utilização de gordura protegida durante o terço inicial da lactação de vacas leiteiras em pastagem de coast-cross. Pesquisa Agropecuária Brasileira, v. 37, n. 10, p. 1503-1509, 2002. 
ZANINE, A. de M. Resposta morfofisiológica em pasto sob pastejo. ColloquiumAgrariae, v. 1, n.2, p. 50-59, 2005. 